\title{
HOW TO DESIGN FOR JOY I SATISFACTION - TWO DIFFERENT APPROACHES ON HOW TO TACKLE THE TASK
}

\author{
Atzberger, Alexander (1); Boffa, Eleonora (2); Montero, Joaquin (1); Paetzold, Kristin (1); Vajna, \\ Sandor (3) \\ 1: Bundeswehr University Munich; 2: KTH Royal Institute of Technology; 3: Otto-von-Guericke \\ University Magdeburg
}

\begin{abstract}
In the course of the IPD International Summer School, two teams addressed the topic of devel-oping an integrated product, with the constraint of it being joyful for the user. One team has chosen an agile development approach whereas the second team approached it in a plan-driven manner. With the starting conditions for both teams being equal, a direct comparison between the agile and plan-driven development approach can be undertaken. The different courses of ac-tion are displayed and the different ways on how to approach the topic of achieving joy for the user are outlined. The results as well as the challenges associated with each approach are dis-cussed and an outlook on the transferability to other fields is given.
\end{abstract}

Keywords: Multi- / Cross- / Trans-disciplinary processes, Collaborative design, Case study

\section{Contact:}

Atzberger, Alexander

Bundeswehr University Munich

Institute for Technical Product Development

Germany

alexander.atzberger@unibw.de 


\section{INTRODUCTION}

Products nowadays are commonly designed for joy or pleasure in order to attract the customer's attention, beyond its mere functional use. This was one of the objectives of the Integrated Product Development International Summer School (IPDISS) 2018. The task, which was presented to the PhD students, was to create a sports device together with the strategy and organisation of its utilisation. In particular, "Design for Joy" was the basic constraint to take into account. The major factor the teams came across was how to keep user motivated and engaged while experiencing joy as a constraint. The students divided into two teams and responded to the given task by applying different approaches: an agile development and a plan-driven approach. These two ways of developing led the teams to different results.

By achieving the goal in an agile manner, the results benefited from the iterations mechanism that refined the idea over and over again in order to address joy, adjusting the features of the product according to users' feedback. Consequently, from a design process point of view, a "design with consumers" pattern was implemented. With the purpose of achieving a successful customer retention strategy, the "design for satisfaction" principle was introduced. The agile development approach challenged the students in terms of how and why to work in an agile manner. Moreover, collaborating in a distributed team led to a misalignment within the group in terms of project development progress, causing delays.

The second team followed a plan-driven approach, pre-defining the action plan of the project and the associated concepts concerning target group and (added) value proposition at the beginning. By doing so, the idea was initially shaped and did not change during the project. Consequently, the team did not develop the product with the customer, but developed the product based on the initial assumptions, thus the user is less involved. Although having a plan of action seems more structured and explicit, there was a lack of clarity in the distribution of responsibilities, which resulted in issues regarding the delivery of results for the specific task blocks, also creating delays.

This contribution aims to present how two different approaches, agile development and traditional development, tackled the task regarding how to introduce the topic of "joy" resp. "satisfaction" for the user in product design. In detail, the research question that the authors identified addresses how the approaches of agile in contrast to traditional development influences the product design process (design with/for customer) in the context of Design for Joy/Satisfaction.

\section{STATE OF THE ART}

\subsection{Product design}

According to the definition of Design given by (Bloch, 2011), a product with its form characteristics should provide the following benefits to the user: First, the utilitarian value, of which the meaning is twofold. On the one hand, it refers to the functional usefulness of a product. On the other hand, the product itself should facilitate the accomplishment of the requested task. Therefore, the product is considered as a mean to satisfy both goals and intentions the user has. Furthermore, in order to create important first impressions and long-term satisfaction among users, hedonic elements namely the aesthetic appeal of the product should be coupled with utilitarian benefits. For instance, a specific physical form of a product would not only attract consumers, but it would also establish a communication between them. In this way, the quality of the user experience by using the product increases, adding even more value to the product. Therefore, the pleasure when using the product is enhanced (Bloch, 1995). Lastly the semiotic benefits relate to the meaning or sign value of a product design. Users interpret the form or design that embeds communicative functions (Bloch, 2011).

Considering the design process from a more holistic perspective, in order to get to successful product design, it is crucial to understand consumer responses to the developed design (i.e. the result of what has been designed). From four different perspectives, (Fenko and van Rompay, 2018) discuss the customer responses to the design of a product. In detail, the designers' perspective clarifies that product form (which leads to aesthetic-related responses) and product function (utilitarian properties) may differ, however they should work together or even complement each other. Considering brand management and product development, the aims of both is the satisfaction of the consumer, which in turn is the managerial perspective. Furthermore, the consumer perspective is related to product experience, spanning from sensory to cognitive and affective reactions. Lastly, the symbolic meaning carried by product designs is emphasized in the semiotic perspective. These four perspectives together built the base for an integrated framework of consumer-driven design. Hence, consumers are involved in the design 
process, steering towards a more interactive way of designing, namely "design with consumers", since the feedback is incorporated into the design process. Summarizing, the focus of designers should be twofold: Firstly, to consider which product form characteristics will deliver the most benefit to the user. Secondly, to understand the consumer responses to a specific design, by analysing them a priori in order to anticipate and address reactions according to what is the company interest.

\subsection{Design for emotion}

Understanding user emotions plays a critical role in order to both anticipate the emotional effects of a product as well as to stimulate intended user responses (Desmet and Hekkert, 2009). Emotions should be captured and become a design tool, introducing them as a co-active aspect in the design process (Halonen et al., 2011). The design approach that brings emotions into the field is called "Design for Emotion" (DfE). In detail, according to the point of view extensively discussed in (Hekkert and Desmet, 2002), the concept of pleasure and emotions is included in the model of the product emotions. Therefore, designers take into account the fact that the interaction product-user leads to an emotional response (Hekkert and Desmet, 2002). The main attempt pursued by the authors is going toward a deep understanding of why a specific product evokes particular emotion effects. In a nutshell, triggered by a personal request (taste, social/design standard, personal goal), the customer evaluates the products leading to an emotional reaction (attraction, praiseworthiness, desirability).

Therefore, the concept of emotion in product design has become paramount to the extent that authors have investigated the field suggesting emotion taxonomies in order to extensively clarify and harmonize the topic. Focusing on positive emotions, (Desmet, 2012) assembled and clustered 25 emotion types. For the scope of this paper, the attention is on two specific emotions responses, Joy and Satisfaction, having in mind that the term "Happiness" defines a state of well-being and contentment and it evokes other emotions (Demirbilek and Sener, 2003). By definition, on the one hand, Joy is "the experience of being pleased about (or taking pleasure in) something or some desirable event". On the other hand, Satisfaction is "the experience of enjoying the recent fulfilment of a need or desire. The experience of joy is the experience that is specifically caused by this fulfilment." (Desmet, 2012). These two emotions arise from different sources during the human-product interaction. In both cases, the basic source is that the product should fulfil well the function it is meant for. What makes the difference between the two emotions is the role the product takes in respect of the activities in which the user is engaged. In case of Joy the product facilitates an activity, making it joyful. On the contrary, Satisfaction enables results, allowing the user to fulfil pre-defined goals for a specific activity. Furthermore, to mark the line between the two emotions, as result of their analysis, (Desmet, 2012) places Joy and Satisfaction in separate clusters, meaning that they are evoked by different appraisals, arousal and associated thought-action tendencies. Thus, Joy belongs to the cluster "Enjoyment", whereas Satisfaction is included in the cluster "Gratification" which gives insights of distinct arousal levels.

In a nutshell, DfE allows exploring the user emotions when interacting with the product. Hence, with this knowledge it is possible to foresee and eventually to address the response the customer would have when using the product. This, in turn, is fundamental to commercialize a successful product design, which impacts on the customer satisfaction.

\subsection{Customer satisfaction}

As stated by (Kiran, 2017), the goal of an organization is primarily to target customer satisfaction. The main reason for steering the focus towards customer satisfaction is enclosed in the potential of satisfied customers. In detail, the majority of the repurchases come from customers that have been satisfied with the company's products.

This section outlines how customer satisfaction has been modelled with regard to product attributes, with particular emphasis to the model developed by Kano. The main idea the Kano model is built upon is the fact that customers perceive the product attributes differently. So that different product requirements influence differently the satisfaction of a customer. On the other hand, this model helps to identify which customer's need is more significant and thus should be satisfied early (Kiran, 2017). Figure 1 presents graphically the concept Kano delivered with his model. In particular, curve A represents the one dimensional requirements, which are usually explicitly demanded by the customer and their fulfilment is proportional to the satisfaction, hence the linear trend. Attractive requirements that customer neither expect or explicitly express follow an exponential pattern (curve B) (Sauerwein et al., 1996). Consequently, customers will not perceive dissatisfaction although the needs are not fully satisfied (Kiran, 2017). Curve C, on the other hand, represents the trend follow by must-be 
requirements, which are taken for granted by customers, hence they do not explicitly demand them. Missing the fulfilment of such attributes would get customers not satisfied and not interested in the product. Competitors' offer might be more attractive (Kiran, 2017; Sauerwein et al., 1996).

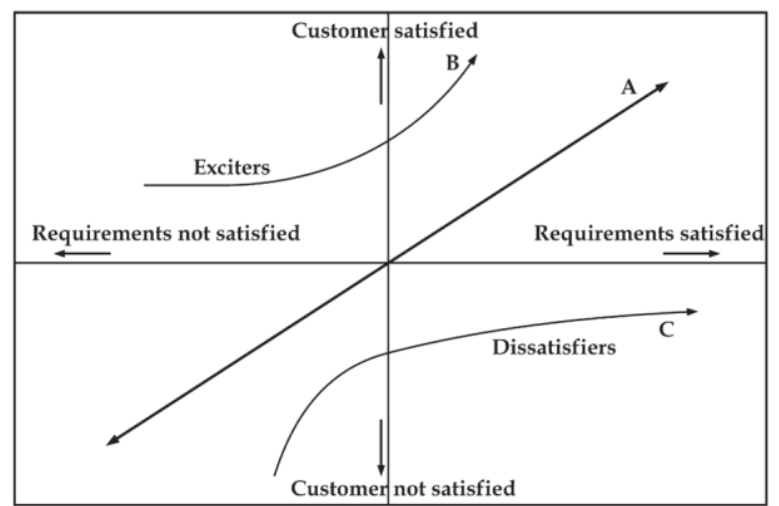

Figure 1 - Display of Kano model, according to (Kiran, 2017)

\subsection{Contrasting traditional and agile development}

To be able to develop in an efficient manner, development approaches such as the V-Modell or the procedure according to VDI 2221, which outline the development logic, but also methods for project support, such as the Stage-Gate-approach, are available nowadays. Those methods promote structured development due to a thorough gathering of all requirements that need to be fulfilled up front in. Based on those requirements, a structured project plan is come up with and followed accordingly, which makes these development approaches very efficient. However, due to prevailing uncertainties and volatility in the context parameters of the development environment, the efficiency of these approaches is being compromised. Of course, those approaches are capable of dealing with requirement changes, yet they are rather designed to prevent those from the beginning due to a thorough requirements management.

Agile development on the other hand is an approach that embraces change. It is referred to as "the capability to react, and adopt to expected and unexpected changes within a dynamic environment constantly and quickly; and to use those changes (if possible) as an advantage." (Böhmer et al., 2015) It is iterative in nature (which certain traditional approaches are as well, such as the spiral model), yet it also incremental, meaning that the goal is to create a prototype within one iteration. Based on this prototype, referred to as increment or MVP (minim viable product), customer or user feedback is acquired and the project goal is adapted. It is very short-cyclic, with iteration lengths of two to four weeks, and thus able to react and adopt to changes very quickly. However, these approaches require a high degree of communication within the team, since a high degree of transparency is necessary to be able to work in an agile manner.

\section{Table 1: Comparison of the characteristics of agile and traditional development} (Nerur and Balijepally, 2007)

\begin{tabular}{|c|c|}
\hline Attribute & Traditional development \\
\hline $\begin{array}{l}\text { Boundary } \\
\text { conditions }\end{array}$ & Stable, foreseeable \\
\hline $\begin{array}{l}\text { Problem solving } \\
\text { approach }\end{array}$ & $\begin{array}{l}\text { Selection of best means to accomplish } \\
\text { given end through well-planned, } \\
\text { formalized activities }\end{array}$ \\
\hline Design process & $\begin{array}{l}\text { Deliberate and formal, linear sequence } \\
\text { of steps, separate formulation and } \\
\text { implementation, rule-driven }\end{array}$ \\
\hline Management style & Command-and-control \\
\hline $\begin{array}{l}\text { Development } \\
\text { model }\end{array}$ & $\begin{array}{l}\text { Life cycle model (waterfall, spiral, or } \\
\text { some variation) }\end{array}$ \\
\hline Control & Process centric \\
\hline Project cycle & Guided by tasks or activities \\
\hline Goal & Optimization \\
\hline
\end{tabular}

Agile development

Turbulent, unforeseeable

Learning through experimentation and introspection, constantly reframing the problem and its solution

Emergent, iterative and exploratory, knowing and action inseparable, beyond formal rules Leadership-and-Collaboration The evolutionary-delivery model

People centric Guided by product features Adaptation, flexibility, responsiveness 
Moreover, such approaches are only beneficial, if the development environment is subject to frequent changes due to a high degree of uncertainty. The characteristics of both development approaches is displayed in Table 1. Agile and traditional development approaches show significant differences and their application strongly depends on the development context. Therefore, no approach is per se better than the other, but favours different aspects and has specific fields of application. Traditional development approaches show benefits in terms of the further development of products, which are not subject to frequent change or large-scale projects, in which several parties are involved. Agile development on the other hand is used for new product development or greenfield projects.

\section{RESEARCH APPROACH}

\subsection{General outline of the task}

The findings in this paper were gathered on processing a project within the IPDISS (Integrated product development International summer school). IPDISS consists of two one-week workshops in Rabat (Malta) and Magdeburg (Germany) in May and September 2018. In the time between these two weeks, the students had the task to develop a business model around a given case. The participants at IPDISS came from different countries all over Europe (France, Italy, Sweden, Germany, Hungary) and Canada. For processing the task, two teams of four students each were set up. Both teams were given the same amount of input and time, starting with the ending of the first week of the summer school in Malta, thus having time to accomplish the task within 14 weeks.

The task given to both teams was as follows: Your group is part of the engineering design team of a large gym equipment manufacturer. You are a hidden champion in the field of gym equipment manufacturing and your task is to come up with a new gym device that incorporates any kind of technical feature (in order to be an integrated product). The expected detailed solution should increase the value for the customer in terms of motivation to work out (e.g. easier integration of training within daily routines, emphasize the effective results of training) supported by business-concept to prepare the commercialisation. In order to leverage on the motivational aspect, the Design for Joy/Satisfaction part comes into play, i.e. the special challenge associated with that task is that the prototype to be developed has to be joyful in the eyes of the user. Therefore, Joy is seen as a mean to boost the motivation to work out in the eyes of the users and, in turn, to keep them as customers for long time.

Since the two teams consisted of different personalities with different backgrounds, also their approaches were utterly different. Team A chose to process this task with an agile development approach whereas team B chose a traditional, plan-driven approach.

\subsection{The two different approaches chosen to fulfil the task}

Team A, consisting of three engineers and one person from the field of business management, decided to approach the given task following the agile development methodology. One of the engineer's research background being the field of agile development, and since both dimensions in the Stacey matrix were relatively unclear (Stacey, 2002), naming the requirements having to be fulfilled (what to do?) and technology to be employed (how to do?), this approach was seen as predestined for that methodology. The logic of agile development is displayed in Figure 2, based on the fuzziness model of (Oestereich and Weiss, 2008). The goal is to reduce the amount of uncertainties (fuzziness) due to an iterative and incremental approach. By the generation of prototypes at the end of all iterations, several uncertainties can be tested and the project scope can be adjusted accordingly. This approach is commonly used when dealing with VUCA environments (VUCA describes a Volatile, Uncertain, Complex and Ambiguous context). Due to the iterative incorporation of the findings, a steep learning curve is the result of this approach.

Team B, consisting solely of engineers, chose a plan-driven approach for their collaboration. Thus, it was considered prudent to appoint a leader having expertise in the field of product development and management. From the beginning, the final objective was fixed and a provisional action plan was created. This plan was strengthened later by means of an online survey that was launched the same day of the creation of the working team. In this way, the period of uncertainty and the vagueness of the definition of tasks were quite short (two weeks), since after obtaining the results of the survey the objectives were strengthened and allowed the leader to clarify the direction the team should take.

This approach has been rather rigid, however very effective and efficient when knowing how to tackle a task and by what means. Due to the clear structure and strong guidelines, the process is basically 
"pre-planned". However, in case the initial assumptions or requirements change, it is quite elaborate to re-align the development process, since the working plan has to be adapted accordingly.
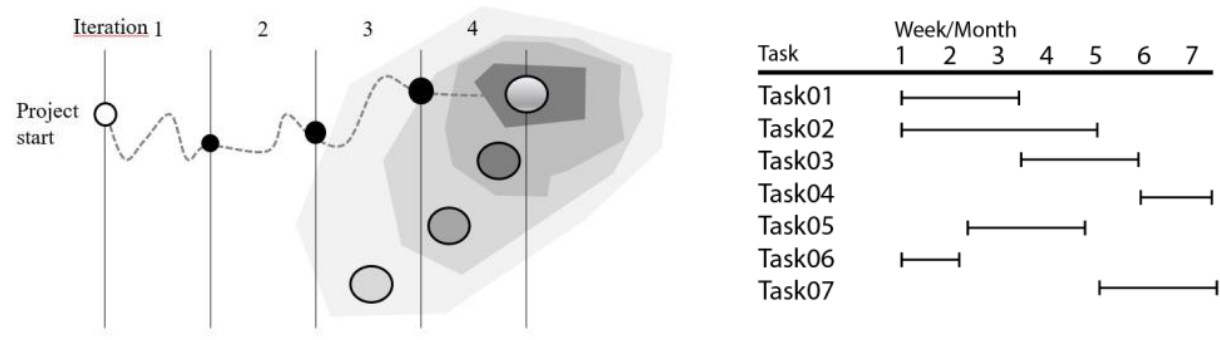

Figure 2 - Agile development approach based on (Oestereich and Weiss, 2008) compared to a traditional, plan-driven approach

With the different approaches chosen, the progress and the overall way of collaboration did vary greatly. In the following chapter, the solid learning throughout the entire project time regarding the topic of joy is elaborated and outlined in more detail. The focus on the actual integrated product solution will be discussed alongside the topic of how to achieve a joyful product, yet the technical solutions are not the focus of this paper.

\section{FINDINGS}

\subsection{Findings gathered using the agile approach - Team A}

The course of action on how to determine what a gym user perceives as a joyful product using the agile approach is displayed in Table 2.

Table 2: Iterative progress displaying the evolution of the idea throughout the iterations

\begin{tabular}{|l|l|l|l|}
\hline Concept stage & Idea & Validation method & Learnings \\
\hline Iteration 1 & Avatar + Journeys (as a game) & $\begin{array}{l}\text { Personal interview with } \\
\text { sportsmen at gym }\end{array}$ & $\begin{array}{l}\text { avatar not accepted, game-like } \\
\text { approach not accepted }\end{array}$ \\
\hline Iteration 2 & $\begin{array}{l}\text { Definition and classification of } \\
\text { the topic joy }\end{array}$ & $\begin{array}{l}\text { Differentiation between joy and } \\
\text { satisfaction, satisfaction more valued by } \\
\text { users than joy in terms of exercising }\end{array}$ \\
\hline Iteration 3 & Fitness companion & 1st online survey & $\begin{array}{l}\text { Survey not clear enough -> participants } \\
\text { did not see benefit of having a fitness } \\
\text { companion, revelation that people want } \\
\text { to know how to perform exercises } \\
\text { correctly }\end{array}$ \\
\hline Iteration 4 & Virtual Personal Trainer (VPT) & $\begin{array}{l}\text { sports department from } \\
\text { university }\end{array}$ & $\begin{array}{l}\text { Need to conduct 2nd survey, feedback } \\
\text { on support tools for exercising }\end{array}$ \\
\hline Iteration 5 & $\begin{array}{l}\text { VPT + overall journey as } \\
\text { progress map }\end{array}$ & $\begin{array}{l}\text { 2nd online survey } \\
\text { as progress tracking feature to uphold } \\
\text { motivation }\end{array}$ \\
\hline
\end{tabular}

The iterations are split into the concept stages, the idea to be tested, the validation methods and the learnings, which had been obtained by the feedback on the respective idea. Given the iterative and incremental nature of agile development, the goal was to answer the question of joyfulness by testing assumptions in every iteration, each iteration lasting approx. two weeks. Based on the feedback, the idea was refined and tested again in the following iteration. Weekly or bi-weekly online meetings were held to exchange the findings and discuss the further progress. Table 1 displays the procedure regarding the idea to be tested, the method to validate it and the learnings gathered by the feedback.

In this case, no MVPs were generated after each iteration. However, uncertainties at the beginning of every iteration were defined (idea), suitable methods to validate the respective uncertainties were used and here, the increments are measures that were used to conduct the validation (survey, interview 
report, literature research). Increments are intended to reduce uncertainties, thus the learnings gathered by the use of the validation method are the necessary feedback needed to refine the initial concept.

Based on the learnings of iteration 5, the remaining project processing time (four weeks) was used to incorporate the finding into an integrated gym machine and the working on the business model. Having determined what needs to be done and how it can be achieved, this was accomplished by having assigned responsibilities to the individual team members in order to setup the final business model and the concept behind it.

Due to the frequent prototyping (producing increments to be tested, such as a drawing or the results of a survey), the idea was aligned according to the feedback received. The initial assumption was that people would enjoy working out, when an avatar would be training with them, like a kind of "training buddy", and to make the training joyful by setting up a game in which several tasks have to be accomplished. Yet, the final result turned out to be a Virtual Personal Trainer, keeping track of the user's progress, showing the user on how to correctly perform the exercises and keeping them motivated by displaying the overall progress of what has already been achieved so far. By understanding the customer's point of view, the team realized that long-term satisfaction is highly valued instead of immediate joy, since the topic of exercising is a long-lasting progress by itself. Thus, the product had to be designed for both short- and long-term satisfaction, in order to attract and keep the customer using the product. It turned out that the result did vary greatly from the initial assumption of what a gym user might consider joyful. This is in strong accordance with the fuzziness model by (Oestereich and Weiss, 2008), as displayed in Figure 2.

\subsection{Findings gathered using the plan driven approach - Team B}

Team B chose to approach the task using a plan-driven approach. After the planning phase, the final action plan was defined with elementary and general definitions, such as the target user, the size of the company and the current market situation. Both business model and action plan were set up following a Gantt diagram, containing different blocks with the tasks to be carried out and the expected objectives after the completion of each block. The team decided to divide its business strategy by targeting two types of clients, end users and fitness centres, thus setting up a business model for both B2C and B2B approaches. The product developed was an advancement of existing machinery for the $\mathrm{B} 2 \mathrm{~B}$ segment and an online platform for B2C.

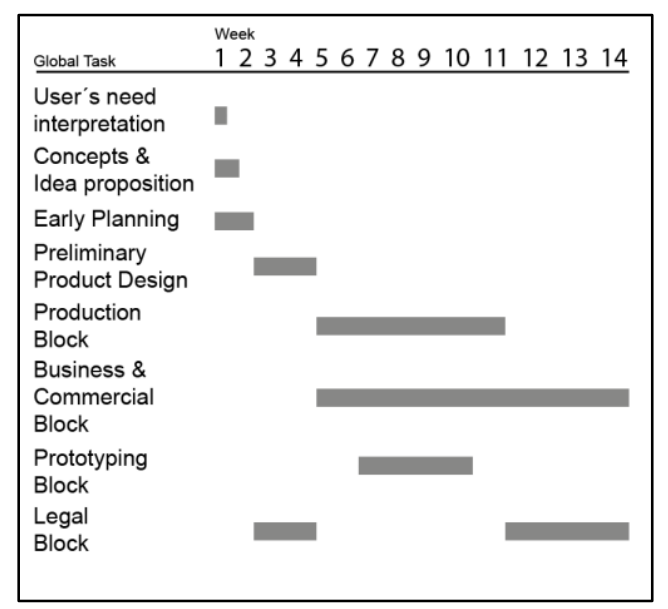

Figure 3 - Gantt diagram displaying the progress of Team B

In the first week of work, a brainstorming was carried out and an online survey was used to identify the needs of the end users, and to make the value proposition for the first segment of clients to be more attractive. Then, the proposal of concepts and ideas was made and the project leader presented the first plan of action. In the fourth week, with the concept already defined, the legal issues were addressed along with the beginning of the design of the product. From week seven until the end of the project, the completion of all the sub-tasks of two large blocks (the production block and the business / market block) was carried out, performing sub-tasks regarding the prototyping blocks and legal issues in the interim. Each block had subtasks with deadlines and associated resources managed by the project leader. The Gantt chart gives an overview over the respective tasks, as displayed in Figure 3. As a result, the business model was developed for a fitness equipment manufacturer producing smart 
products, such as fitness trackers that generate large amount of data, which can be used to improve user fitness. The concept pursues the strategy of entering the market by establishing business relationships with fitness centres (B2B) in order to acquire fitness centre users as customers in the long term (B2C). The goal is to bring joy to the final user by highlighting her / his progress and with the data gathered, offering additional products to match their lifestyle.

\section{DIscussion}

\subsection{Design for satisfaction}

In this context, the Design for long-term satisfaction (LTS) turned out to have a higher value compared to the fulfilment of immediate joy. Processing the IPDISS project proved this concept, although similar insights concerning the aforementioned distinction could be observed in the examined literature. According to (Desmet, 2012) Joy and Satisfaction belong to different clusters. Hence, both different arousal levels and different level of user engagement express the existing gap between these two emotions: Joy and Satisfaction are seen as separate concepts and distinct responses to a products design. This allows Team A to investigate more the field and to suggest, which emotion should be in focus when companies pursue a customer retention strategy. Particularly in the fitness environment, the motivation is a very important factor. In order to keep the customer, products should have features that engage and commit users, since a lot of effort needs to be put in the training to get the desired results. Thus, in this context, "catchy" features will not be enough: customers are attracted, the attraction leads to a purchase, but the customer does not come back. Here, the design for long-term satisfaction comes into play, in which the level of user engagement seems to be an enabler. In detail, the more the product design engages customers, the longer the satisfaction will be, and the longer the customers will keep purchasing company's products. Accordingly, (Fenko and van Rompay, 2018) state that a brand loyalty emerges from a satisfied customer, who in turn has a greater willing to pay higher prices for such products. In this vein, with the present article authors suggest that LTS should be included in product requirements, although this is going in the opposite way from how customer satisfaction has been modelled so far (i.e. Kano model), namely customer satisfaction in comparison with product requirements affecting each other.

In conclusion, to strive for customer satisfaction has been outlined as the goal of an organization. A majority of the repurchases comes from customers who are satisfied with the company's products. Therefore, customer satisfaction plays an important role in customer retention (Kiran, 2017). Within this context, a "design with users" approach seems to be the most suitable way to structure the design process. By doing so, companies get a broader and comprehensive understanding of their customers and the uncertainty in term of requirements and technology decreases. Therefore, the final product is aligned to the customer's desire. Besides, given the experience gained with the summer school project the agile development method seems to facilitate the integration of the customer in the design process. Thanks to its iterative nature, the initial hypothesis on "joyful" features are refined step by step, according to the feedback gained from the customers. Therefore, a high value to the Joy/Satisfaction dimension arises. It becomes the centre of the design process, further suggested to be part of the product requirements.

On the other hand, it is important for firms not to get blind by totally following the customer will. The majority of customers do not know what they really want (Davenport et al., 2011).

On the contrary, team B with its business strategy focused more the technical aspects that would make the users enjoy and thus value their product, given the presumption that the users always want to improve their fitness situation. As mentioned in the previous section, the objective of this business plan is to make the first step in the B2B market and then reach the B2C market, in order to exploit in the future the benefits of having a large number of customers. Therefore, long-term customer satisfaction is focused on keeping the customer over-satisfied by offering unexpected requirements in low-cost products in order to maintain and to increase the level of satisfaction of new and old users, as explained in curve B of the Kano Model in Figure 1. The intention of the retention strategy is clearly seen when the company offers the user a smart watch with access to a digital platform (B2C model) without any cost, included in the person's subscription to the fitness centre that uses the machines of the company (B2B model). It needs to be pointed out, that in this business model the lack of motivation of the end-user does have a tremendous impact. It will lead the clients to perceive dissatisfaction and under the minimum 
signal that their needs are not fully satisfied, they may change to the product of a competitor. This fact would cause losing the continuity of the user in the system (database). The latter is the worst scenario for the business model, considering the objective of the company is to obtain the user's health data overtime, the long-term goal would be seriously endangered. Therefore, it is important to highlight that in order for this business model to work, it is necessary to maintain the focus on giving the end user joy whilst using the products. Maintaining long-lasting joy for an indefinite period of time is definitely very difficult to achieve, since the feedback and the involvement of the clients is diminished. That is why the professionals in charge of this area inside of a company must precisely know how to read the needs of the end users belonging to this niche.

\subsection{Challenges associated with each approach}

With Team A having decided to work in an agile manner due to the fact that several uncertainties were apparent at the beginning and one team member has his research background in that type of field, several challenges arose in this team. First of all, to establish the understanding of why and how to work in an agile manner was underestimated and could not be achieved for everybody in the team. Thus, some team members did not see the benefits in working that way and tended to ask for tasks to be accomplished. However, in an agile team, the role of a team leader does not exist and the team members agree together, as a group, which tasks they are going to be perform throughout the next iteration. In the course of the project, it was decided that the researcher in the agile field took the lead regarding the team organisation. However, the decision was made within the group, in order to avoid a command-and-control work style. Since agile development is leaving options open, communication is one key aspect in this way of collaborating. Because of the team members were distributed all over Europe, weekly and biweekly meetings were performed using Skype, which was a very timeconsuming matter, yet necessary in order to be flexible. If one was unable to attend a meeting, it was very hard for that respective person to keep up with the ongoing development progress since the course of action was changing throughout the iterations - even though everything was documented. Agile development relies on physical or virtual presence, active communication, and information flows. It works best when the team is co-located. Team distribution is a major challenge in this context, and it requires a lot of motivation and commitment (Conforto et al., 2014).

Although the plan-driven approach team $\mathrm{B}$ had chosen was rather rigid, the results that can be obtained with such an approach can be very promising, yet this strongly depends on the clarity expressed by the project leader. It is important to note that all the details and characteristics were decided in advance to be able to have a coherent plan from the beginning. The team members interpreted both satisfaction and joy of the user in the first design stage and the concept was fixed until the end of the project. Given this rigidity, several problems arose during the completion of the task sub-blocks, mainly related to the lack of clarity in the delegation of responsibilities to other team members. As project leader schedules the course of action in the beginning, the project plan has to be followed accordingly. Yet, especially when the tasks are not properly defined, some team members tend to underestimate the complexity of the task, which results in a partial or no completion when the deadline arrives. It was experienced that the leader's conviction has to be strong enough to allocate the right tasks to the right team members to avoid this type of delay. On the other hand, given that some deadlines inevitably moved, the tasks seemed disconnected from the project as a whole. This resulted in confusion by the team members, who ultimately showed a lack of commitment because they did not understand the true utility and importance of tasks. Since each member is very different in the sociocultural aspect in addition to the time difference between continents, it is reflected very clearly that the tasks must be precise and objective, so that the team can keep the continuity of work.

Yet two important aspects regarding the limitations of the work need to pointed out. First, these findings were gathered in the course of a Summer School project by students, which have their focus on product development, yet lack long-term development experience. Thus, the results are able to initiate first considerations on how projects in such field might be tackled by companies, yet further research with experienced personnel is necessary to underpin the validity of the findings at hand. An additional fact that needs to be pointed out is that personal fitness is an area where people have to put in a lot of effort to obtain results, which is why long-term satisfaction is (of course) more valued in this context. 


\section{OUTLOOK}

In this paper, the findings of the IPDISS summer school 2018 are displayed. Given the task of developing an integrated product, the topic of joy had to be addressed as a constraint. Two teams consisting of four students each decided to tackle this task on different ways, an agile development and a plan-driven approach. The agile development teams' focus was to fully comprehend what a gym user would consider to be joyful when exercising. The plan-driven teams' focus built their business model around initial assumptions what a gym user might consider joyful and intended to deliver the best technical solution possible - thus satisfying the user. Since none of the students were experts in the field of gym components nor the Design for Joy, difficulties in addressing the tasks arose. Additionally, with the team members living in different countries, such a cross-national collaboration was perceived challenging. Yet, both teams focused on creating long-term satisfaction for the users, since this is valued more in the context of exercising in gyms. However, such linkages might also be valid in other contexts besides personal fitness, when a considerable amount of money has to be invested. Thus, the results might be transferable to further topics, which has to be validated in the future.

\section{REFERENCES}

Bloch, P.H. (1995), "Seeting the ideal form: Product design and consumer response", Journal of Marketing, Vol. 59 No. 3, pp. 16-29.

Bloch, P.H. (2011), "Product design and marketing: Reflections after fifteen years", Journal of Product Innovation Management, Vol. 28 No. 3, pp. 378-380.

Böhmer, A., Beckmann, A. and Lindemann, U. (2015), "Open Innovation Ecosystem - Makerspaces within an Agile Innovation Process", In: Eelko Huizingh, Steffen Conn and I. Bitran, (Ed.), Proceedings of the ISPIM Innovation Summit: Changing the Innovation Landscape, The International Society for Innovation Management, Brisbane, pp. 1-11.

Conforto, E., Salum, F., Amaral, D., da Silva, S.L. and deAlmeida, L.F.M. (2014), "Can Agile Project Managemet Be Adopted by Industries Other than Software Development?", Project Management Journal, Vol. 45 No. 3, pp. 21-34.

Davenport, T., Dalle Mule, L. and Lucker, J. (2011), "Know what your customers want before they do", Harvard Business Review.

Demirbilek, O. and Sener, B. (2003), "Product design, semantics and emotional response", Ergonomics, Vol. 46 No. 13-14, pp. 1346-1360.

Desmet, P.M.A. (2012), "Faces of product pleasure: 25 positive emotions in human-product interactions", International Journal of Design, Vol. 6 No. 2, pp. 1-29.

Desmet, P.M.A. and Hekkert, P. (2009), "Special issue editorial: Design \& Emotion", International Journal of Market Research, Vol. 55 No. 6.

Fenko, A. and van Rompay, T.J.L. (2018), Consumer-Driven Product Design, Methods in Consumer Research, Volume 2: Alternative Approaches and Special Applications, Vol. 2, Elsevier Ltd, available at: https://doi.org/10.1016/B978-0-08-101743-2.00018-2.

Halonen, E., Pynttäri, V., Lilja, J., Sillanpää, H., Mäntysalo, M., Heikkinen, J., Mäkinen, R., et al. (2011), "Environmental protection of inkjet-printed Ag conductors", Microelectronic Engineering, Vol. 88 No. 9, pp. 2970-2976.

Hekkert, P. and Desmet, P.M.A. (2002), “The Basis of Product Emotions”, Pleasure with Products: Beyond Usability, pp. 60-68.

Kiran, D.R. (2017), "Customer Satisfaction, Total Quality Management", Elsevier, pp. 125-141.

Nerur, S. and Balijepally, V. (2007), "Theoretical reflections on agile development methodologies", Communications of the ACM, Vol. 50 No. 3, pp. 79-83.

Oestereich, B. and Weiss, C. (2008), APM - Agiles Projektmanagement, dpunkt Verlag.

Sauerwein, E., Bailom, F., Matzler, K. and Hinterhuber, H.H. (1996), "The Kano Model: How to Delight Your Customers", International Working Seminar on Production Economics, pp. 313-327.

Stacey, R. (2002), "Organizations as complex responsive processes of relating", Journal of Innovative Management, Vol. 8 No. 2.

\section{ACKNOWLEDGMENTS}

The findings were gathered during the course of the 2018 IPD International summer school. The authors would like to thank Sylvain Bolifraud, Kötöny Balint, Marvin Richrath, Kousay Samir and Julia Guerineau for their participation and the joyful exchange of work-related topics and also the supervising professors Kristin Paetzold, Jonathan Borg, and Sandor Vajna for their assistance and helpful advices. 